\title{
İndetermine koledok darlıklarında fırça sitolojisinin değeri: Şişli Etfal deneyimi
}

\author{
Diagnostic yield of brush cytology in indeterminate biliary strictures: Şişli Etfal experience
}

Ali Rıza KÖKSAL ${ }^{1}$, Meltem ERGÜN ${ }^{1}$, Hüseyin ALKIM $^{1}$, Salih BOĞA ${ }^{1}$, Mehmet BAYRAM ${ }^{1}$, Banu YILMAZ ÖZGÜVEN ${ }^{2}$, Muharrem BATTAL ${ }^{3}$, Canan ALKIM ${ }^{1}$

Şişli Hamidiye Etfal Eğitim ve Araștırma Hastanesi, ${ }^{1}$ Gastroenteroloji Kliniği, ${ }^{2}$ Patoloji Kliniği, ${ }^{3}$ Genel Cerrahi Kliniğ̌̆, Istanbul

Giriş ve Amaç: Endoskopik retrograd kolanjiopankreatografi esnasinda alınan fırça sitolojisi şüpheli koledok darlıkları tanısında yaygın olarak kullanılmaktadır. Çalışmamızda kliniğimizde şüpheli koledok darlığı olan olgulardan alınan firça sitolojisi sonuçlarının sensitivite, spesifite, pozitif prediktif değer ve negatif prediktif değerini değerlendirmeyi amaçladık. Gereç-Yöntem: Ocak 2013 ile Nisan 2014 tarihleri arasinda endoskopik retrograd kolanjiopankreatografi sırasında malign darlıktan şüphelenilerek firça sitolojisi yapılan hastalarin demografik verileri, endoskopik retrograd kolanjiopankreatografi raporları, patoloji raporları ve varsa endoskopik retrograd kolanjiopankreatografi sonrası ameliyat/görüntüleme eșliğinde biyopsi bulguları ve hastalı̆ın seyri ve hastaların sürvileri retrospektif olarak incelendi. Bulgular Ocak 2013 ile Nisan 2014 tarihleri arasında 35 hastaya 37 işlem yapılarak

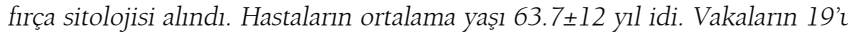
kadın, 16'sı erkekti. Sitolojik değerlendirme sonuçlarmna göre, 3 olguda adenokanser, 1 olguda ileri dereceli displazi ve 1 olguda düşük dereceli displazi saptandi. Sitolojik incelemelerin 20'si hücresel değerlendirme için materyal yeterli ve malignite negatif (2'si tekrar), 3'ü yetersiz materyal ve 9'u indetermine olarak raporland. Fırça sitolojisi malign olan 4 olgunun tanısı diğer yöntemlerle de doğrulandı. Düşük dereceli displazili hastada ek inceleme yoktu. Malignite negatif olan 18 hastanın 13'ünün takip verilerine ulaşıldı. Bu 13 hastanin 10'unda takip incelemeleri ile malignite saptanmazken, 3'ünde malignite saptandi. Ayrica sitoloji sonucu yeterli olmayan ya da indetermine tespit edilen 12 hastanın 3'ünde çeșitli tetkik ve girișimlerle karsinom tanısı konuldu, 9 hastada malignite yoktu. Doğruluk analizi yapıldığında firça sitolojisi için sensitivite \%57.1, spesifite \%100, pozitif prediktif değer \%100 ve negatif prediktif değer \%76.9 olarak hesaplandı. Sonuç: Malign koledok darlığı șüphesi olan olgularda firça sitolojisinin pozitif prediktif değeri yüksek olmakla birlikte negatif gelmesi maligniteyi ekarte ettirmemekte; malignite şüphesi kuvvetli olan olgularda incelemenin diğer tetkiklerle desteklenmesi gereklidir.

Anahtar kelimeler: Endoskopik retrograd kolanjiopankreatografi, koledok, firça sitolojisi

\section{GİRISS}

Tıkanma sarılığı ile başvuran hastalarda endoskopik retrograd kolanjiopankreatikografi (ERCP) yapıldığında sık karşılaşılan bulgulardan biri de safra yolu darlıklarıdır (Şekil 1) (1). Bu darlıklar inflamasyon, post operatif değişiklikler gibi benign nedenlere bağlı olabileceği gibi kolanjiokarsinom, pankreas başı karsinomu gibi malign nedenlere de bağlı olabilir (2-5). Malign, benign ayrımının yapılması, tedavileri birbirinden tamamen farklı olduğundan, son derece önemlidir. Bu amaçla intraduktal safra aspirasyon sitolojisi, koledok içinden firça (brush) sitoloji, endobiliyer forseps biyopsisi, çekilen plastik biliyer stent ya da firça ucunun sitopatolojik incelemesi ve endosonografi eşliğinde ince iğne aspirasyon biyopsisi yapıl-
Backgaround and Aims: Endoscopic retrograde cholangio pancreatogaphy guided bile duct cytology for the diagnosis of indeterminate bile duct strictures is commonly used. The aim of this study was to define sensitivity, specificity, and positive and negative predictive values of endoscopic retrograde cholangio pancreatogaphy brush cytology from indeterminate biliary strictures. Materials and Methods: We retrospectively analyzed diagnostic yield of brush cytology in indeterminate biliary strictures in our single center, between January 2013 and April 2014. Demographic data, endoscopic retrograde cholangio pancreatogaphy reports, pathology reports, post-endoscopic retrograde cholangio pancreatogaphy operation, percutaneous biopsy results, the course of the disease and survival of the patients were recorded. Results: Cytologic examination of thirty seven samples were done in 35 patients. The mean age of patients was $63.7 \pm 12$ years. There were 19 females and 16 males. Three patients had adenocarcinoma, one high grade dysplasia and one low grade dysplasia, which were detected at cytological evaluation. Twenty samples were reported as normal with sufficient material; 3 were reported as insufficient material; and 9 were reported as indeterminate. The diagnosis of malignancy was confirmed with other methods in 4 patients. Follow-up data was obtained in 13 of 18 malignancy negative patients. Ten of the 13 patients were detected negative for malignancy and 3 were diagnosed malignant with additional examinations. Also, 3 out of 12 patients whose cytological results were insufficient or indeterminate were diagnosed malignant after additional examinations; the remaining 9 patients were found negative for malignancy. In accuracy analysis, the sensitivity of brush cytology was calculated as $57.1 \%$, specificity $100 \%$, positive predictive value $100 \%$ and negative predictive value $76.9 \%$. Conclusion: In cases with indeterminate biliary strictures, positive predictive value of brush cytology was high but negative cytology results do not exclude malignancy. Cases with high suspicion of malignancy must be evaluated with additional examinations.

Key words: Endoscopic retrograde cholangio pancreatogaphy, common bile duct, brush cytology

ması gibi işlemler yapılmaktadır. Bu işlemler içerisinde fırça sitolojisi uygulama kolaylığı, güvenilirliği ve ulaşılabilirliği nedeniyle birçok endoskopist tarafindan tercih edilmektedir (Resim 1). Buna rağmen alınan materyalin patolojik değerlendirme için yetersiz olabilmesi, işleme bağlı reaktif değişikliklerin histopatolojik olarak maligniteden ayrımının zorluğu, tanısal başarı oranlarını düşürmektedir (Resim 2) (6). Çalışmamızda, ERCP sırasında koledok darlığı nedeniyle firça sitolojisi yapılan olguların patoloji sonuçlarını değerlendirmek ve olguların nihai tanıları ile fırça sitoloji tanılarını karşılaştırarak bu işlemin tanıya katkısını araştırmak amaçlanmıştır. 


\section{GEREÇ VE YÖNTEM}

Ocak 2013 ile Nisan 2014 tarihleri arasında kliniğimize t1kanma sarılığı ile başvuran, ERCP yapılarak koledok darlığı saptanan ve fırça sitolojisi alınan vakaların patoloji sonuçları retrospektif olarak değerlendirildi. Demografik veriler, ERCP bulguları, sitolojiye gönderilen lam sayları ve varsa ERCP sonrası ameliyat/görüntüleme eşliğinde biyopsi bulguları, hastalığın seyri ve hastaların sürvileri incelendi. Fırça sitoloji sonuçları, hepatobiliyer alanda deneyimli, tek patolog tarafından yeniden değerlendirildi (Resim 3). Vakalar sitoloji sonucuna göre dört grupta değerlendirildi. 1) Benign sitoloji bulguları 2) Malign ya da displastik değişiklikler 3) Benign malign ayrımı yapilamayan indetermine olgular 4) Materyal yetersiz olan olgular. Ayrica hastalar ameliyat, görüntüleme ya da ileri tetkikler gibi takip verilerine göre malign ya da benign grubuna dahil edildi. Ölüm bildirim sistemi veri tabanı

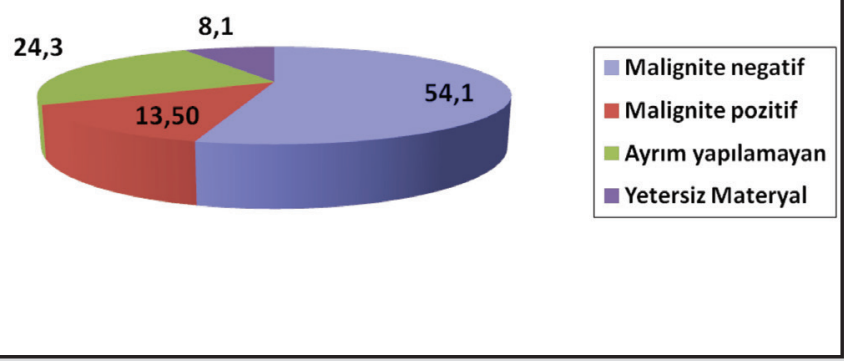

Şekil 1. Fırça sitoloji incelemelerinin patolojik tanı dağılımları.

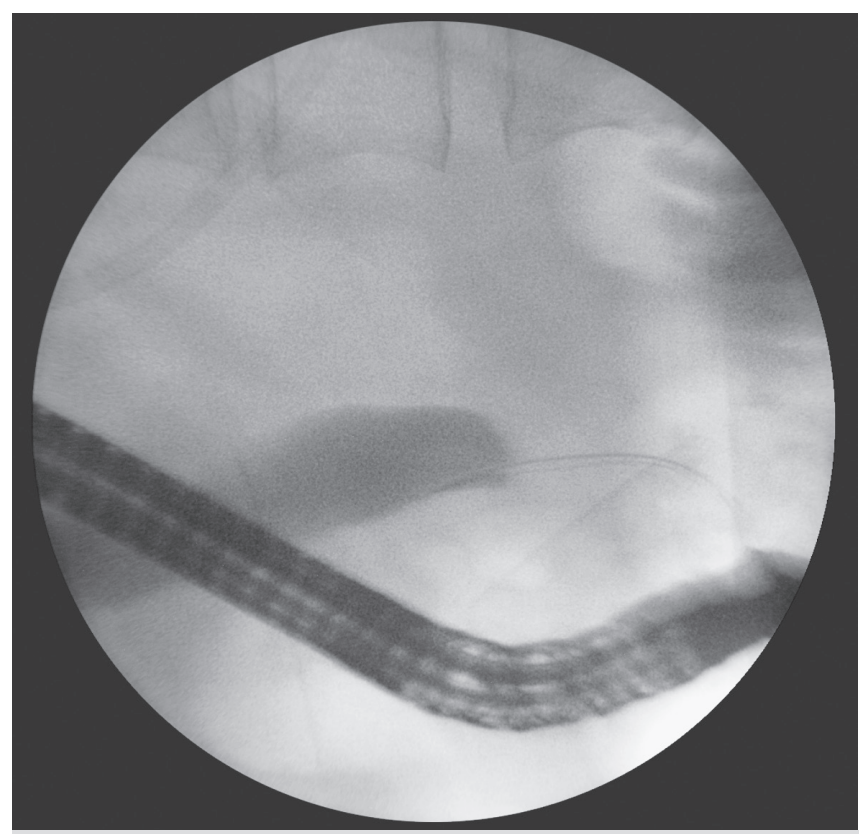

Resim 1. Koledok darlığı ERCP görüntüsü. kullanılarak hastaların survi değerlendirmesi yapıldı. Nihai tanı olarak malign ve benign grupların fırça sitoloji sonuçları karşılaştırılarak sensitivite spesifite değerlendirmesi yapıldı.

\section{BULGULAR}

Toplam 35 hastadan yapılan 37 firça sitolojisi değerlendirildi.

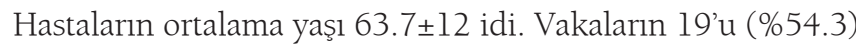
kadın, 16'sı (\%45.7) erkekti. Sitolojik değerlendirme sonuçlarına göre, 5 (\%13.5) olguda malignite ya da displazik değişiklikler mevcuttu. Bu olgulardan 3'ünde adenokanser, 1 olguda ileri dereceli displazi ve 1 olguda düşük dereceli displazi saptandı. Sitolojik incelemelerin 20'si (\%54.1) hücresel değerlendirme için materyal yeterli ve malignite negatif (2'si tekrar), 3'ü (\%8.1) yetersiz materyal ve 9'u (\%24,3) indetermine olarak raporlandı (Tablo 1).

Firça sitolojisi sırasında sürüntü yapılan lam sayısı ortalama 4.9 (1-11) idi. Patoloji sonucu benign olan olgular ile malign olan olgular arasında lam sayısı açısından istatistiksel olarak anlamlı farklılık bulunmadı $(4.7 \pm 0.4,4.4 \pm 0.5, \mathrm{p}=0,58)$. Ilk sitoloji sonucu yetersiz olan ve işlem tekrarlanan 2 olguda ikinci sitoloji sonuçları da negatif olarak değerlendirildi.

Hastaların takip, tetkik, inceleme ve girişimleri sonucunda nihai tanı olarak 15 (\%42.9) hastada benign nedenler tespit edilirken, 10 (\%28.6) hasta ise malign olarak değerlendirildi ve 10 (\%28.6) hastanın nihai tanısına ulaşılamadı. Nihai tanısı benign olan 15 vakanın 5'inde mükerrer ERCP, 5 'inde kontrol magnetik rezonans kolanjiopankreatografi (MRCP) ve klinik takip, 2'sinde dış merkezde endosonografi eşliğin-

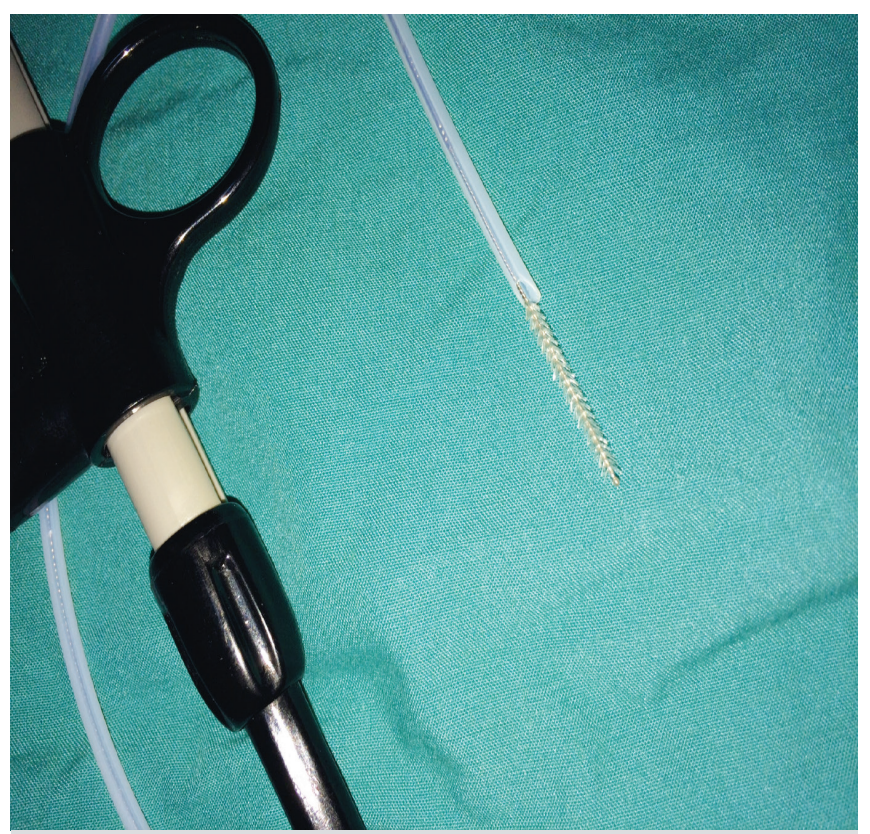

Resim 2. Koledok sitoloji fırçası. 


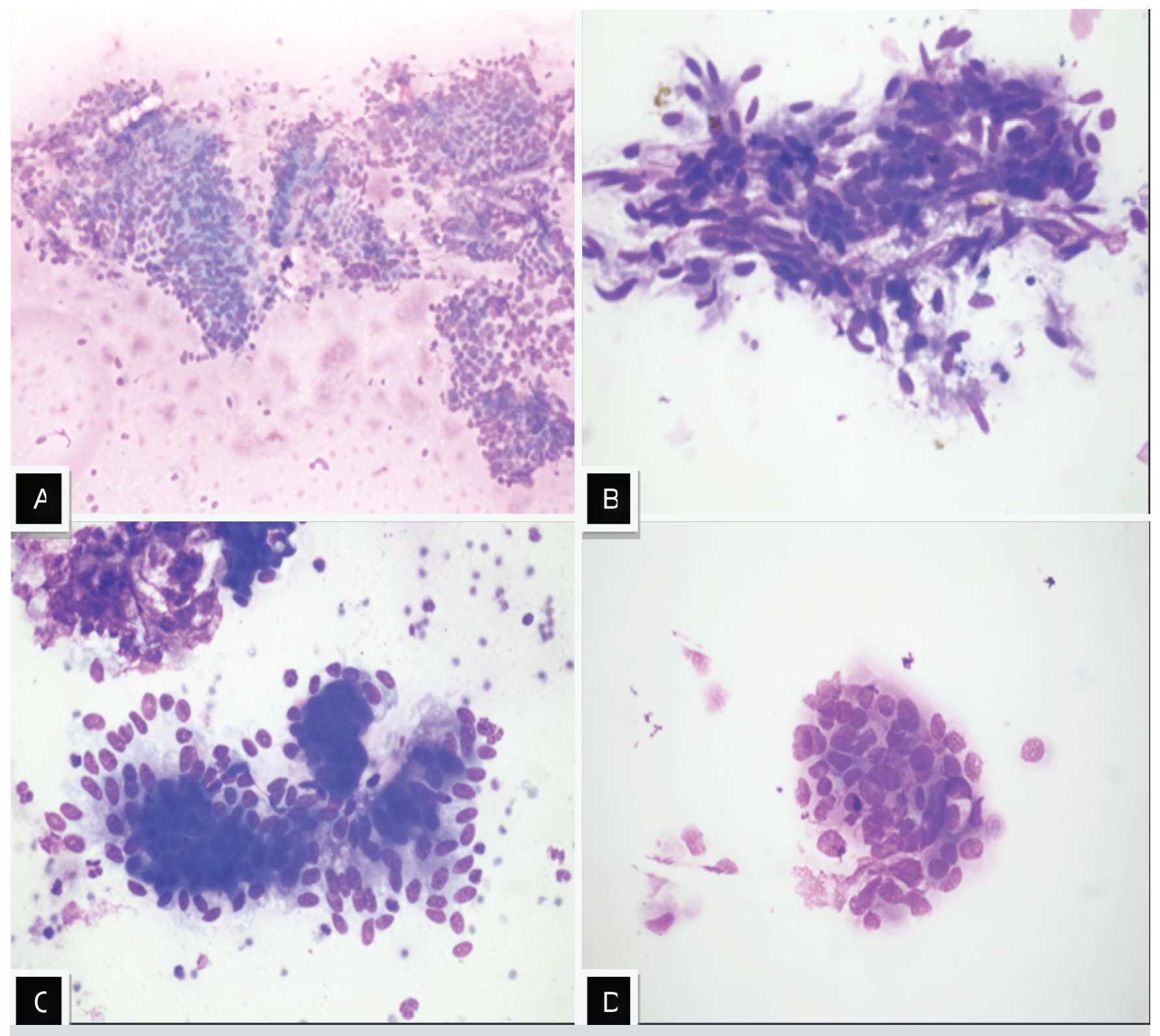

Resim 3.A Fırça sitolojisinde normal safra duktus epitel hücrelerinin kohezivitesini koruyan, tek tabaka halinde dizilim gösteren bal peteği görünümü. MGG, x200 B: Fırça sitolojisinde duktus hücrelerinde artefaktif "feathering" görünümü, MGG, x400 C: tri, pleomorfik, hiperkromatik nükleuslu, geniş eosinofilik sitoplazmalı, üç boyutlu, kohezivitesi bozulmuş, gevşek kümeler oluşturan atipik epitelyal hücreler, MGG, x400 D: Iri pleomorfik, hiperkromatik nükleuslu, üç boyutlu gruplar oluşturan atipik epitelyal hücreler, MGG,X400 (MGG: May-Grunwald-Giemsa).

de (FNA) ince iğne aspirasyon biyopsisi, l'inde laparoskopik biyopsi, l'inde tomografi eşliğinde biyopsi, l'inde başka bir nedenle yapılan cerrahi sırasında tanı konmuştu. Nihai tanısı malign olan 10 vakanın 5'inde tomografi eşliğinde biyopsi, 3'ünde Whipple operasyonu sonrası, l'inde laparoskopik biyopsi, l'inde perkütan transhepatik kolanjiografi (PTK) s1rasında alınan biyopsi ile tanı konulmuştu. Benign nedenler arasında en sık koledokolitiazis varken malign nedenlerde en sık pankreas başı karsinomu mevcuttu (Tablo 1). Takipler sırasinda 12 hasta eksitus oldu. Bu hastalarda sitoloji sonrası ortalama survi $169 \pm 162$ gün idi.
Fırça sitolojisi ile adenokanser saptanan 3 hastanın 2'sine Whipple ameliyatı yapıldı. Ameliyat sonu patolojisi de sitoloji sonucu ile uyumlu idi. Fırça sitolojisi ile adenokanser saptanan 3. olgu laparoskopik incelemede inoperabl olarak değerlendirildi. İleri dereceli displazi saptanan bir olguda perkütan biyopsi ile malignite tanısı doğrulanarak kemoterapi başlandı. Düşük dereceli displazi saptanan hastada ek inceleme yapılmadığından hastayla ilgili herhangi bir değerlendirme yapilamadi.

Sitolojik değerlendirmeye göre malignite negatif olan 18 hastanın 13'ünün takip verilerine ulaşıldı. Bu 13 hasta- 


\section{Tablo 1. Fırça sitolojisi sonuçları ve klinik tanıların dağılımı}

\begin{tabular}{|c|c|c|c|c|c|}
\hline \multicolumn{2}{|l|}{ Firça Sitoloji Sonucu } & \multicolumn{2}{|l|}{ Ileri Tetkik Girişim Operasyon } & \multicolumn{2}{|l|}{ Nihai Tanı } \\
\hline \multirow{6}{*}{ Malignite Negatif } & \multirow{6}{*}{18} & Görüntüleme eşliğinde biyopsi & 3 & Koledokolitiazis & 8 \\
\hline & & Koledok kisti nedeniyle hepatikojejunostomi & 1 & Pankreas başı CA & 1 \\
\hline & & Laparoskopik biyopsi & 2 & Kolanjiosellüler CA & 2 \\
\hline & & Veri yok & 5 & Exitus & 5 \\
\hline & & Diğer yöntemler, takip görüntüleme & 7 & Kronik pankreatit & 1 \\
\hline & & & & Kist hidatik & 1 \\
\hline \multirow{3}{*}{$\begin{array}{l}\text { Malignite ya da } \\
\text { Displazik Değişiklikler } \\
\text { Pozitif }\end{array}$} & \multirow{3}{*}{5} & Whipple operasyonu & 2 & Pankreas başı CA & 4 \\
\hline & & Görüntüleme eşliğinde biyopsi & 2 & Exitus & 1 \\
\hline & & Exitus- veri yok & 1 & & \\
\hline \multirow{4}{*}{ Ayrım Yapılamayan Olgular } & \multirow{4}{*}{9} & Whipple operasyonu & 1 & Koledokolitiazis & 4 \\
\hline & & Görüntüleme eşliğinde biyopsi & 1 & Pankreas başı CA & 2 \\
\hline & & Veri yok & 3 & Veri yok & 3 \\
\hline & & Diğer yöntemler takip görüntüleme & 4 & & \\
\hline \multirow{3}{*}{ Yetersiz Materyal } & \multirow{3}{*}{3} & PTK sırasında biyopsi & 1 & Kolanjiosellüler CA & 1 \\
\hline & & Diğer yöntemler takip görüntüleme & 1 & Koledokolitiazis & 1 \\
\hline & & Veri yok & 1 & Veri yok & 1 \\
\hline
\end{tabular}

nın 10'unda takip incelemeleri ile malignite saptanmazken, 3'ünde malignite saptandı. Sitoloji sonucu yeterli olmayan ya da indetermine tespit edilen 12 hastanın 3'ünde çeşitli tetkik ve girişimlerle karsinom tanısı konuldu, 9 hastada malignite yoktu. Bu bulgulara göre, firça sitolojisi ile kanser veya displazi saptanan 5 olgunun 4'ünde ve kesin negatif saptanan 13 hastanın 10'unda sitolojik değerlendirme kesin tanı ile uyumlu bulundu (Tablo 2). Doğruluk analizi yapıldığında firça sitolojisi için sensitivite $\% 57.1$, spesifite $\% 100$, pozitif prediktif değer \%100 ve negatif prediktif değer \%76.9 olarak hesaplandi.

\section{Tablo 2. Fırça sitoloji sonuçları ve klinik tanıların karşı-} laştırması

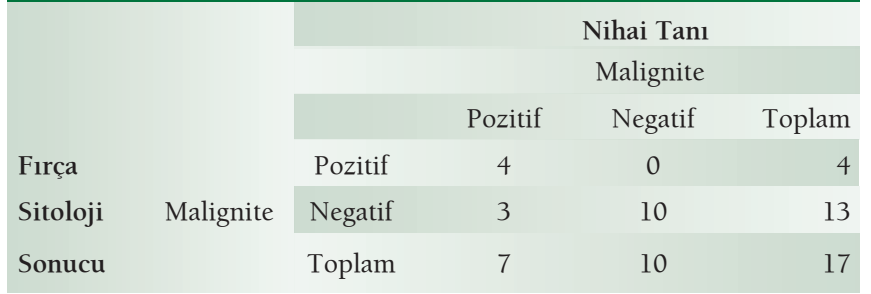

\section{TARTISSMA}

Tıkanma ikteri ile başvuran hastalarda ERCP sırasında biliyer darlıklara sıkça rastlanmaktadır (1). Bu darlıkların etyolojisine yönelik işlem esnasında fırça sitolojisi alınması basit, hızlı ve güvenilir olması nedeniyle tercih edilmektedir. Ancak alınacak örneğin bazen yeterli olmayışı, yalancı negatiflik oranlarının yüksekliği, histopatolojik değerlendirmede inflamatu- var süreç malignite ayrımının yapılamaması gibi etkenler fırça sitolojisinin etkinliğini sınırlamaktadır (1-6). Literatürde fırça sitolojisi ile ilgili yayınlarda örnek kalitesini artırmak amacıyla, işlemin tekrarlanması, aynı seansta yapılan biyopsi ile kombine edilmesi, fiksatör kullanılması, darlık içerisinden daha fazla sayıda geçiş yapılması veya bu işlem için geliştirilen farklı fırçaların kullanılması önerilmektedir (7-10). Son yıllarda lezyonu direkt olarak gösteren ve aynı seansta biyopsi alınabilmesine olanak tanıyan endosonografi ve kolanjioskopi gibi yöntemler, indetermine biliyer darlıklarda tanısal başarı oranlarını artırmıştır. Buna rağmen özellikle ülkemiz koşullarında bu yöntemlere ulaşılamayan durumlarda firça sitolojisi halen tanıya yardımcı önemli bir basamaktır.

Fırça sitolojisi sırasında alınan materyalin yetersizliği ya da malignite konusunda net ayrım yapılamaması durumunda fırça sitolojisi işlemi tekrarlanabilir. Lopez Jurado ve ark.'nın yaptığı bir çalışmada ilk sitolojik incelemesi yetersiz ya da malignite açısından kuşkulu olarak değerlendirilen 8 hastaya yapılan ikinci sitolojik incelemede bu hastaların 5'inde malignite tanısı doğrulanmıştır (1). Bizim çalışmamızda ise yetersiz materyal olan iki vakada tekrarlanan sitoloji sonucu yine malignite negatif olarak bulundu. Bu sonuç her iki hastada da ileri tetkik ve incelemelerle doğrulandı. Literatürde lam sayısı ya da yayma miktarının tanısal doğruluk üzerine etkisini gösteren çalışma bulunamamıştır. Bizim çalışmamızda vaka sayısı az olmasına rağmen malign ve benign sitoloji sonuçları arasında incelenen örnek sayısı bakımından fark bulunmamıştır.

Fırça sitolojisi ile ilgili yapılmış çalışmalarda sensitivite oranları \% 18-60 arasında değişmektedir. Ancak birçok çalışmada 
spesifite oranları \%95-100 şeklinde değişmektedir. Bizim çalışmamızda da literatürdeki veriler ile uyumlu biçimde sensitivite oranı \%57.1, spesifite \%100 olarak bulundu.

Biliyer darlık yapan lezyonların zor ulaşılabilir olması, hastaların genelde terminal dönemde tanı alması, yaşlı ve komorbid problemleri olması nedeniye birçok hastanın fırça sitolojisi dışında tanı şansı olmamaktadır (11). Nitekim 12 hastanın eksitus olduğu çalışmamızda bu hastalardan 6 (\%50)'sında tanı için ileri inceleme yapılamadan hastalar kaybedilmiştir.

\section{KAYNAKLAR:}

1. Temiño López-Jurado R, Cacho Acosta G, Argüelles Pintos M, et al. Diagnostic yield of brush cytology for biliary stenosis during ERCP. Rev Esp Enferm Dig 2009;101:385-9, 390-4.

2. De Bellis M, Sherman S, Fogel EL, et al. Tissue sampling at ERCP in suspected malignant biliary strictures (Part 1). Gastrointest Endosc 2002;56:552-61.

3. De Bellis M, Sherman S, Fogel EL, et al. Tissue sampling at ERCP in suspected malignant biliary strictures (Part 2). Gastrointest Endosc. 2002;56:720-30

4. Dickson PV, Behrman SW. Distal cholangiocarcinoma. Surg Clin North Am 2014;94:325-42.

5. García-Cano J. Endoscopic management of benign biliary strictures. Curr Gastroenterol Rep 2013;15:336.

6. Mansfield JC, Griffin SM, Wadehra V, Matthewson K. A prospective evaluation of cytology from biliary strictures. Gut 1997;40:671-7.
Indetermine biliyer darlıkların tanısında kullanılan endosonografi, kolanjioskopi gibi yeni yöntemler ile firça sitolojisinin tanısal gücünü karşılaştıran geniş hasta sayılı prospektif randomize çalışmalara ihtiyaç vardır.

Biliyer darlık olgularında fırça sitolojisinin sensitivitesi düşük olmakla birlikte spesifitesi yüksektir. Bu olgularda basit güvenli ve hızlı sonuç alınan bir yöntem olarak rutin fırça sitolojisi uygulanmalıdır. Bununla birlikte sitoloji negatif gelen olgularda incelemenin diğer tetkiklerle desteklenmesi gereklidir.

7. Moreno Luna LE, Kipp B, Halling KC, et al. Advanced cytologic techniques for the detection of malignant pancreatobiliary strictures. Gastroenterology 2006;131:1064-72.

8. Weber A, von Weyhern C, Fend F, et al. Endoscopic transpapillary brush cytology and forceps biopsy in patients with hilar cholangiocarcinoma. World J Gastroenterol 2008;14:1097-101.

9. Shieh FK, Luong-Player A, Khara HS, et al. Improved endoscopic retrograde cholangiopancreatography brush increases diagnostic yield of malignant biliary strictures. World J Gastrointest Endosc 2014;6:312-7.

10. Urbano M, Rosa A, Gomes D, et al. Team approach to ERCP-directed single-brush cytology for the diagnosis of malignancy. Rev Esp Enferm Dig 2008; 100:462-5.

11. Joo I, Lee JM. Imaging bile duct tumors: pathologic concepts, classification, and early tumor detection. Abdom Imaging 2013;38:1334-50. 